\title{
Elucidation of Underlying Mechanisms by Which Millettia macrophylla Benth Induces Its Estrogenic Activity
}

\author{
Stéphane Zingue, ${ }^{1,2}$ Chantal Beatrice Magne Nde, ${ }^{3}$ Colin Clyne, ${ }^{3}$ and Dieudonné Njamen ${ }^{2}$ \\ ${ }^{1}$ Laboratory of Physiology, Department of Life and Earth Sciences, Higher Teachers' Training College, University of Maroua, \\ P.O. Box 55, Maroua, Cameroon \\ ${ }^{2}$ Laboratory of Animal Physiology, Department of Animal Biology and Physiology, Faculty of Science, University of Yaounde I, \\ P.O. Box 812, Yaounde, Cameroon \\ ${ }^{3}$ MIMR-PHI Institute of Medical Research, Departments of Molecular and Translational Sciences, Monash University, \\ 246 Clayton Road, Level 4, VIC 3168, Melbourne, Australia
}

Correspondence should be addressed to Dieudonné Njamen; dnjamen@gmail.com

Received 31 March 2014; Accepted 28 May 2014; Published 10 August 2014

Academic Editor: Fermin Sanchez de Medina

Copyright () 2014 Stéphane Zingue et al. This is an open access article distributed under the Creative Commons Attribution License, which permits unrestricted use, distribution, and reproduction in any medium, provided the original work is properly cited.

\begin{abstract}
Millettia macrophylla is used traditionally to treat menopause related symptoms. This plant was shown to exhibit estrogenic effects in vitro on human embryonic kidney cells and in vivo on ovariectomized rats. The present study aimed at elucidating underlying mechanisms by which M. macrophylla induced its estrogenic effects. To accomplish our goal, kidney Hek293T cells transiently transfected with estrogen alpha or beta receptor expression plasmids were cotreated with a pure antiestrogen ICI 182,780 and the dichloromethane or methanol soluble fractions of M. macrophylla. To follow up, we cotreated ovariectomized rats with both extracts and ICI 182,780 for 3 days in the classical uterotrophic assay. Animals were then sacrificed and the uterine wet weight, total protein levels in uteri, uterine, and vaginal epithelial heights, and mammary gland were assessed. In vitro, the results suggested that the induction of the estrogenic activity by M. macrophylla is due to the binding of its secondary metabolites to $\mathrm{ER} \alpha$ and $\mathrm{ER} \beta$. In vivo, the cotreatment of extracts and ICI 182,780 significantly abrogated the biological responses induced by the extracts alone. Taken together, these results indicate that the active principles of $M$. macrophylla induce their beneficial effects on menopausal symptoms by activating the ERs.
\end{abstract}

\section{Introduction}

Throughout the ages, plants have been the major source of medication for the treatment of diverse diseases and continue to be a major source of primary health care for today's populations in most areas of the world [1]. The medicinal value of plants has therefore been recognized by almost every society on this planet [2]. In the developing countries in particular, $80 \%$ of the population still resort to traditional medicine for their primary health care [3]. For instance, the use of traditional herbal medicine is popular in Central Africa, particularly in Cameroon, mainly because of economic constraints and the strength of traditional beliefs $[4,5]$. In our ongoing search for bioactive compounds from medicinal plants [6-10], we have been studying the stem bark of Millettia macrophylla, a Cameroonian medicinal plant used in the treatment of menopausal symptoms.

Millettia macrophylla, also known as Millettia aboensis, is used to alleviate sexual transmitted diseases, as well as some symptoms related to menopausal complaints, like other species of Millettia genus such as $M$. conraui, $M$. drastica, M. griffoniana, M. zechiana, M. barteri, and M. dura [1117]. Since there were no scientific data to support the above claims, we therefore evaluated the beneficial effects of $M$. macrophylla extracts on menopausal symptoms, in order to scientifically justify the claimed beneficial effects. Using a model of rats exhibiting menopause-like symptoms in vivo and cells overexpressing estrogen receptors alpha or beta $(\mathrm{ER} \alpha$ or $\mathrm{ER} \beta)$ in vitro, we previously showed that DCM and $\mathrm{MeOH}$ extracts of M. macrophylla mimic estrogen-like 
effects on the genital tract and increase estrogen receptors transactivity, respectively [18]. These results suggest that $M$. macrophylla may contain secondary metabolites that bind ERs or alter coregulators of ERs. However, the mechanism of actions that underpin the aforementioned effects is still unknown. Therefore, we aimed to elucidate the underlying mechanisms by which M. macrophylla induces its estrogenic effects. To accomplish our goal, DCM and $\mathrm{MeOH}$ soluble fractions of $M$. macrophylla were used with a pure and well-characterized antiestrogen ICI 182,780 in a cotreatment regimen in vitro on cells transiently transfected with the estrogen $\alpha$ or $\beta$ receptor expression plasmids and in vivo in ovariectomized rats.

\section{Material and Methods}

2.1. Substances. The pure antiestrogen ICI 182,780 (7-[9[4,4,5,5,5-pentafluoropentyl) sulfinyl [nonyl]-estra-1,3,5(10)triene-3,17diol) and 17 $\beta$-3-benzoate (E2B) (Estr-1, 3,5 (10)trien-3, $16 \alpha, 17 \beta$-triol) were obtained from Sigma-Aldrich (Hamburg, Germany). The HEK293T cells that contain the SV40 large T-antigen were purchased from ATCC (The Global Bioresource Center, Australia). Luciferase reporter construct was kindly provided by Dr. Simon Chu (Prince Henry's Institute of Medical Research, Australia). Cells were transfected using Lipofectamine Reagent obtained from Invitrogen (Sydney, Australia).

2.2. Plant Material. The stem barks of Millettia macrophylla were harvested at the former reserve of Ediki (Kumba, southwest region of Cameroon) in January 2010. Our botanical sample was identified and authenticated by Mr. Victor Nana, botanist at the National Herbarium of Cameroon (HNC) in Yaounde (voucher specimen number 49654/HNC). The welldried and pulverized stem bark of M. macrophylla (2500 g) was macerated in 10 liters of dichloromethane (DCM) for $72 \mathrm{~h}$ at room temperature, and $25 \mathrm{~g}$ of extract was obtained after filtration and evaporation of the solvent using a rotary evaporator in vacuum. The residue insoluble material was thereafter steeped in 10 liters of methanol for $72 \mathrm{~h}(\mathrm{MeOH})$, filtered through Whatman paper $\mathrm{N}^{\circ} 4$, and concentrated to give $53.4 \mathrm{~g}$ of methanol extract of M. macrophylla. For phytochemical analysis of these extracts, the LC analyses were performed on a Thermo Finnigan HPLC system consisting of a vacuum degasser (Discovery SUPELCO HS C-18 column $(25 \times 4.6 \mathrm{~mm}, 5 \mu \mathrm{m}$ particle size $))$, a quaternary pump, an autosampler, and a DAD (diode array detector) (Thermo Finnigan, San Jose, CA) as previously reported [18].

2.3. Animal Models. Fifty female Wistar rats (Rattus norvegicus [19]) aged 3 months (250 g) were obtained from the breeding facility of the Laboratory of Animal Physiology, University of Yaounde 1, Cameroon. They had free access to a standard soy-free rat chow and water ab libitum. Animal housing and experiments were carried out following the guidelines of the institutional Ethics Committee of the Cameroon Ministry of Scientific Research and Technological Innovation, which has adopted the guidelines established by the European Union on animal care (CEE Council 86/609).

\subsection{Study Design}

2.4.1. Experiment 1: In Vitro Antagonization of $M$. macrophylla Extracts with ICI 182,780. In a previous study, we have found that M. macrophylla extracts are able to transactivate the estrogen receptors $\alpha$ and $\beta$, in human embryonic kidney 293T cell line (HEK293T) [18]. In the present study, we investigated whether this transactivation is lost in the presence of a pure antiestrogen ICI 182,780. To accomplish our goal, HEK293T were transiently transfected with the estrogen $\alpha$ receptor expression plasmid (200 ng-HEK293T-ER $\alpha$ cells) or the estrogen $\beta$ receptor expression plasmid (200 ng-HEK293TER $\beta$ cells), together with the double estrogen response element (ERE) fused to a luciferase reporter (250 ng-(ERE)2tk-Luc) plasmid and $\beta$-galactosidase reporter plasmid using Lipofectamine Reagent. They were then treated with different concentrations of M. macrophylla extracts alone or in combination with ICI $182,780(500 \mathrm{nM})$ for $24 \mathrm{~h}$. Cells treated with E2 (10 nM) served as positive control. Luciferase reporter gene assays were performed using a commercial kit (Promega, Australia) according to the manufacturer's instructions. Luciferase activity was measured and normalised against $\beta$-galactosidase activity determined by using the 2-nitrophenyl $\beta$-D-galactopyranoside (ONPG) method (Sigma-Aldrich, Sydney, Australia). Each experiment was performed in at least duplicate and repeated three times.

2.4.2. Experiment 2: In Vivo Antagonization of M. macrophylla Extracts with ICI 182,780. This experiment aimed to elucidate whether the estrogenic activity observed in vivo with $M$. macrophylla extracts is mediated through ERs. All substances (E2B, ICI 182,780, and M. macrophylla extracts) used in this experiment were dissolved in olive oil. The injection volume was $0.3 \mathrm{~mL}$ subcutaneously.

Fifty female Wistar rats were ovariectomized. Fourteen days after endogenous hormonal decline, animals were randomly distributed into 10 groups of 5 rats each. Five animal groups were treated as follows. The negative control received the vehicle (olive oil) and the positive control was treated with estradiol benzoate (E2B) at the dose of $0.75 \mu \mathrm{g} / \mathrm{kg} \mathrm{BW} / \mathrm{d}$. Three groups received either DCM extract at the dose of $300 \mathrm{mg} / \mathrm{kg}$ or $\mathrm{MeOH}$ extract at the doses of 100 and $300 \mathrm{mg} / \mathrm{kg} \mathrm{BW} / \mathrm{d}$. The last remaining five groups were treated with the same substances and at the same doses combined with ICI 182,780 at the dose of $300 \mu \mathrm{g} / \mathrm{kg}$ BW/d. After the 3day treatment, animals were sacrificed; the uterine weight, total protein levels in uteri, uterine, and vaginal epithelial heights, and mammary gland were assessed.

2.5. Biochemical Analysis. Total uterine protein levels were determined in uteri using colorimetric methods described by Gornall et al. [20].

2.6. Histological Analysis. The histomorphological parameters of mammary gland, uteri, and vagina were assessed as described previously [18].

2.7. Statistical Analysis. The data from each experimental group were expressed as mean \pm SEM. One-way analysis of the variance (ANOVA) followed by Dunnett's test for multiple 


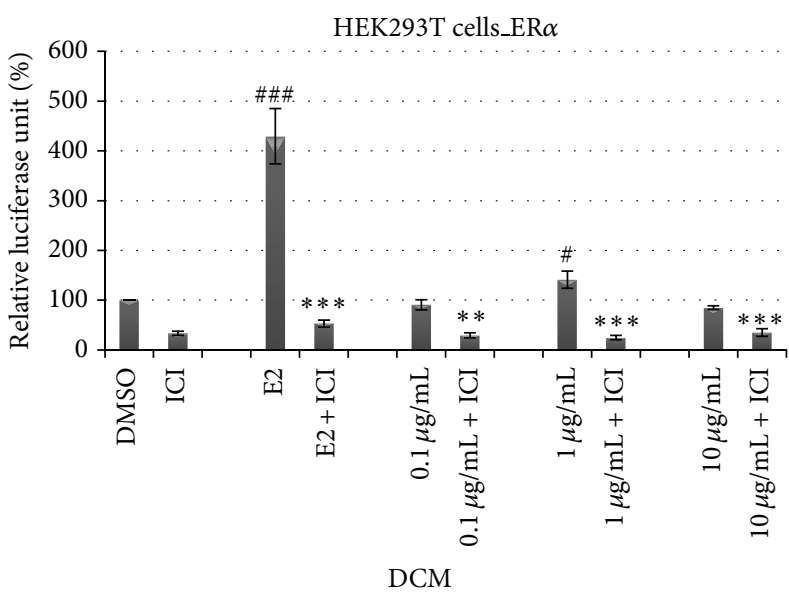

(a)

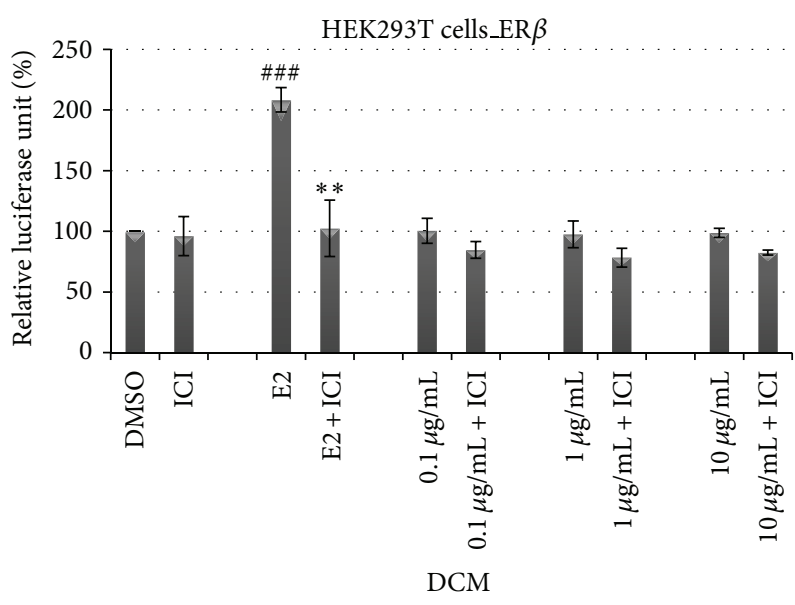

(c)

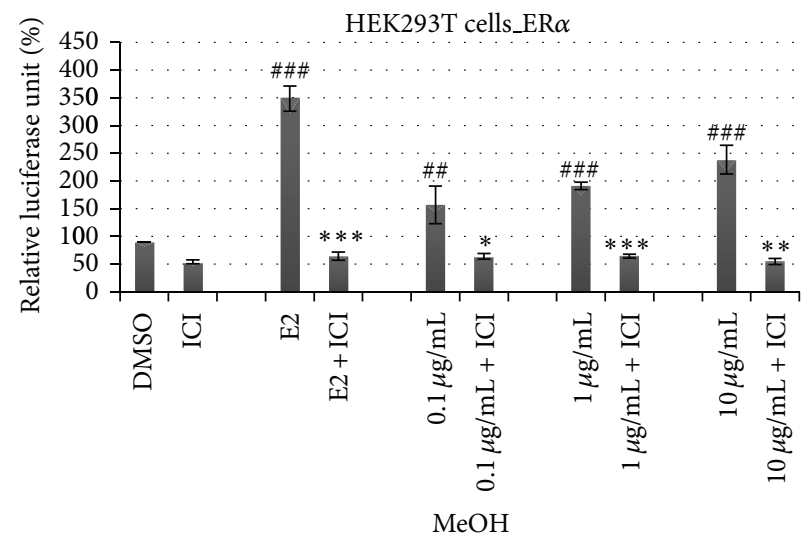

(b)

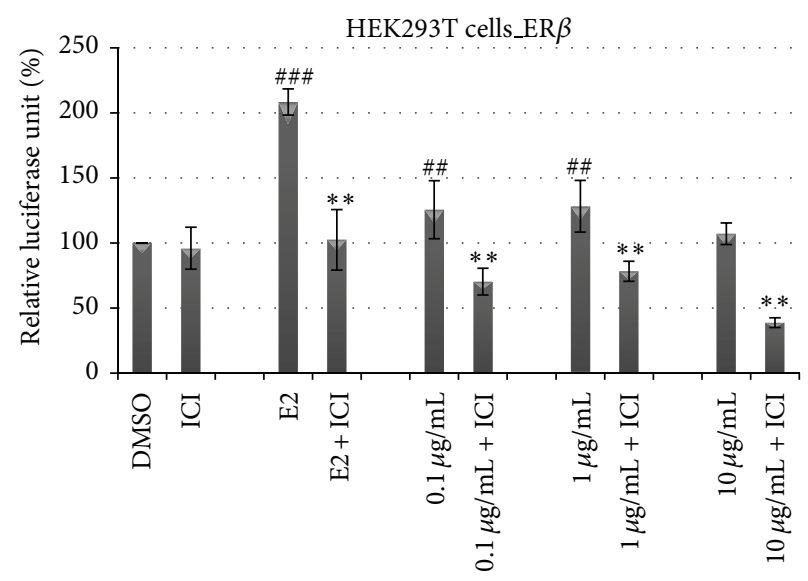

$\mathrm{MeOH}$

(d)

Figure 1: Effects of DCM and MeOH extracts on the activation of estrogen $\alpha$ and $\beta$ receptors in HEK293T cells in the absence or in the presence of ICI 182,780 at $500 \mathrm{nM}$. The effect of DCM and MeOH extracts on estrogen $\alpha$ and $\beta$ receptors activity in the transiently transfected HEK293T-ER $\alpha$ and HEK293T-ER $\beta$ cells was investigated by measuring reporter gene-coupled luciferase activity. The relative luciferase units (RLU) were measured in the presence of DMSO $(0.1 \%)$, E2 $(10 \mathrm{nM}), \mathrm{DCM}$, and MeOH extracts. ${ }^{\#} P<0.05,{ }^{\# \#} P<0.01$, and ${ }^{\# \# \#} P<0.001$ compared with control; ${ }^{*} P<0.05,{ }^{* *} P<0.01$, and ${ }^{* * *} P<0.001$ compared with the same dose of each substance without ICI 182,780 .

comparisons and the Student's $t$-test was used for statistical comparison between different control and treated groups for in vivo and in vitro experiments, respectively. The significance of the difference was fixed at $P<0.05$.

\section{Results}

3.1. In Vitro Antagonization of M. macrophylla Extracts with ICI 182,780. As expected, ICI 182,780 significantly $(P<$ 0.001 ) blocked the transactivation induced by $\mathrm{E} 2$ alone in both HEK-ER $\alpha$ and HEK-ER $\beta$ (Figure 1). The results obtained after cotreatment of HEK293T cell lines transiently transfected with ER $\alpha$ and ER $\beta$ showed a significant inhibition $(P<0.001)$ with $M$. macrophylla extracts and ICI 182,780 (Figure 1). This result confirms that M. macrophylla extracts induced their in vitro activity through ERs.
3.2. In Vivo Antagonization of M. macrophylla Extracts with ICI 182,780. Regarding the uterine parameters, after the in vivo 3-day treatment, antiestrogen ICI 182,780 (Faslodex: $300 \mu \mathrm{g} / \mathrm{kg})$ totally abrogated $(P<0.001)$ the increase of uterine wet weight induced by E2B (Figure 2(a)), and it significantly $(P<0.01)$ decreased uterine total protein level (Figure 2(b)) and uterine epithelial height (Figures $2(\mathrm{c})$ and $2(\mathrm{~d}))$. Compared with DCM treated group, the cotreatment of animal with DCM extract and ICI 182,780 induced a significant $(P<0.01)$ decrease in the uterine wet weight. $\mathrm{MeOH}$ extract did not increase the uterine wet weight. However, it did significantly $(P<0.01)$ increase total protein levels and uterine epithelial height. ICI 182,780 significantly blocked the increase of these aforementioned parameters when cotreated with DCM and $\mathrm{MeOH}$ extracts (Figures 2(b), 2(c), and 2(d)). 


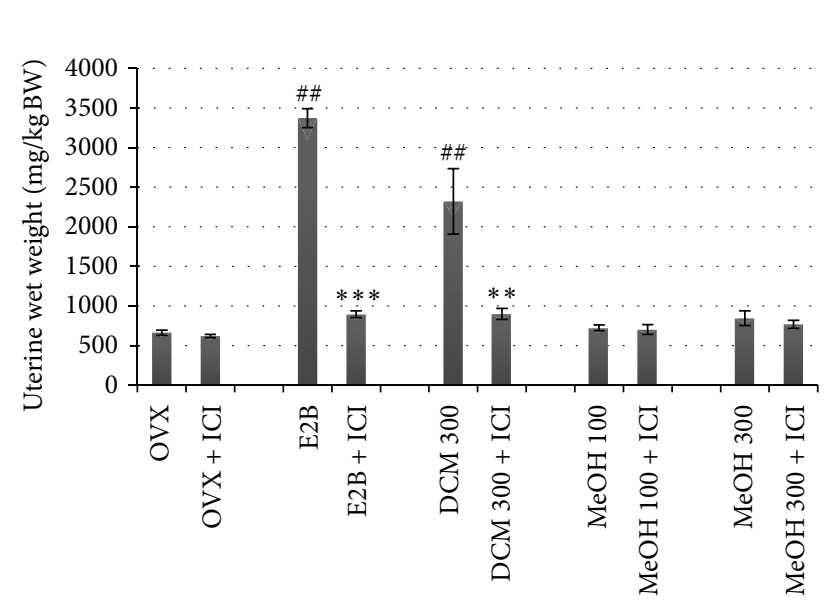

Treatment

(a)

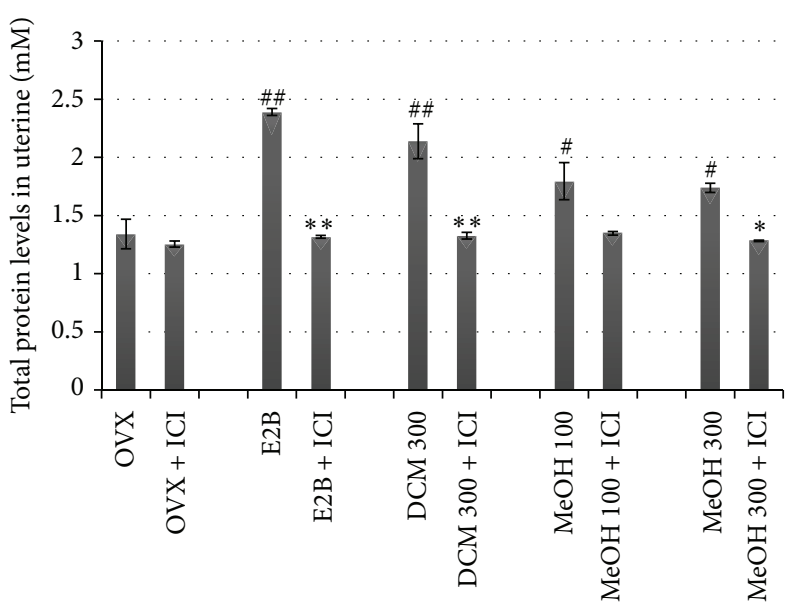

Treatment

(b)

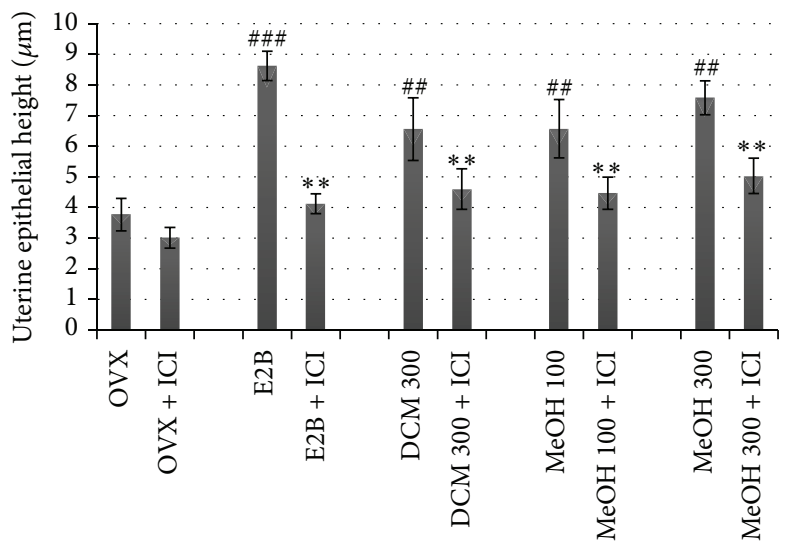

Treatment

(c)
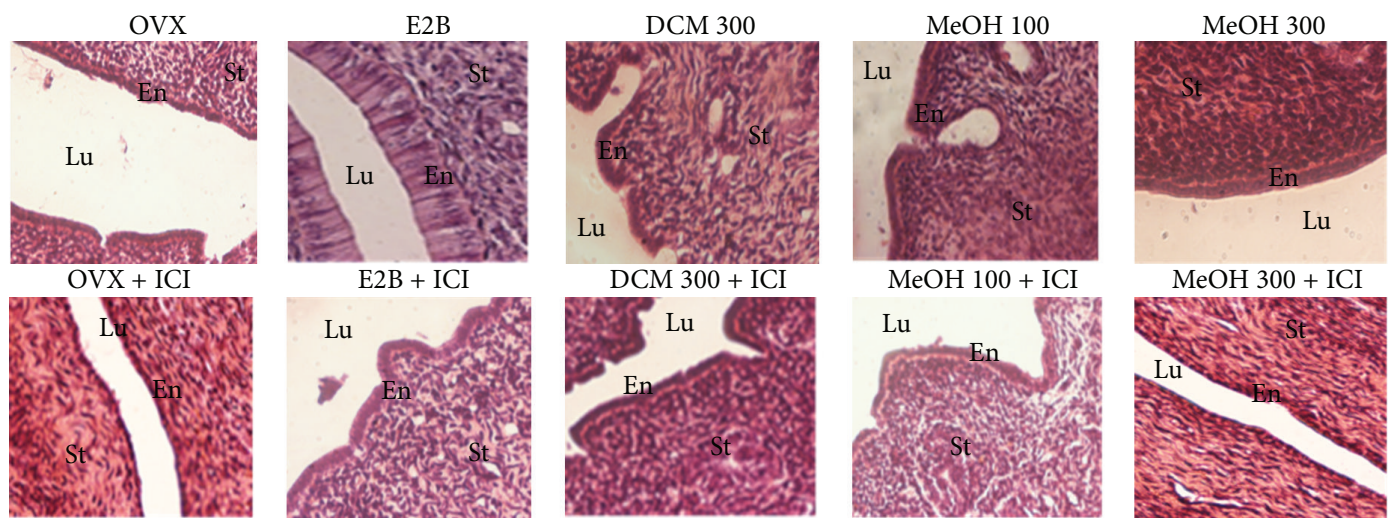

$\mathrm{MeOH} 300$ + ICI

(d)

FIGURE 2: Effects of 3-day treatment with M. macrophylla extracts combined or not with ICI 182,780 on the uterine wet weight (a), total protein levels in uterine (b), uterine epithelial height (c), and microphotographs (d). OVX = OVX animals treated with the vehicle (OVX); $\mathrm{E} 2 \mathrm{~B}=\mathrm{OVX}$ animals treated with estradiol benzoate at $0.75 \mu \mathrm{g} / \mathrm{kg} \mathrm{BW}$; DCM $=$ OVX animals treated with the dichloromethane extract of M. macrophylla; $\mathrm{MeOH}=\mathrm{OVX}$ animals treated with the methanol extract of $M$. macrophylla. ${ }^{\#} P<0.05,{ }^{\# \#} P<0.01$, and ${ }^{\# \#} P<0.001$ compared with control; ${ }^{*} P<0.05,{ }^{* *} P<0.01$, and ${ }^{* * *} P<0.001$ compared with the same dose of each substance without ICI 182,780 . Lu: lumen; En: Endometrium; St: Stroma. 


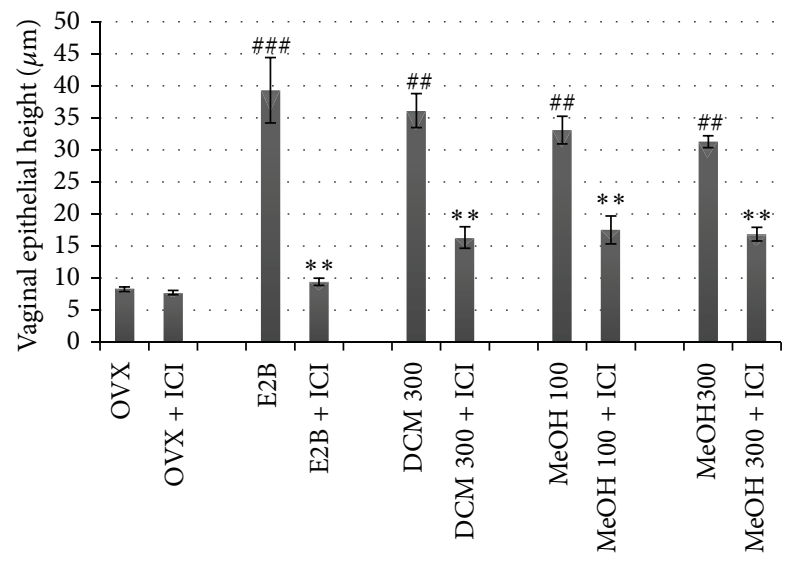

Treatment

(a)

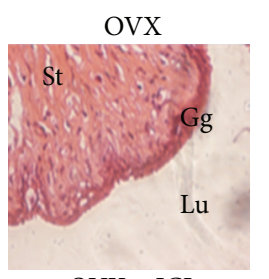

$\mathrm{OVX}+\mathrm{ICI}$

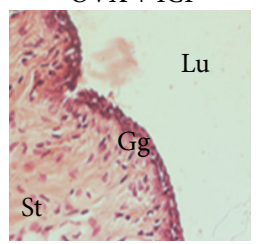

E2B

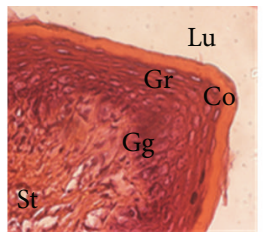

$\mathrm{E} 2 \mathrm{~B}+\mathrm{ICI}$

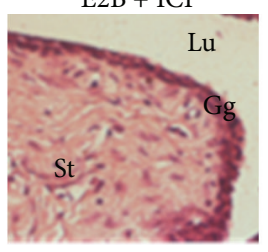

DCM 300

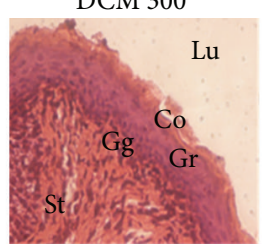

DCM $300+$ ICI

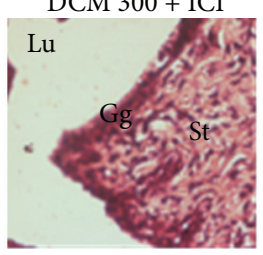

$\mathrm{MeOH} 100$

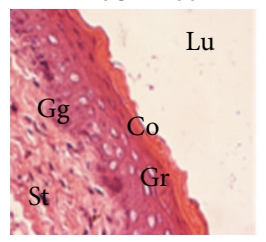

$\mathrm{MeOH} 100+\mathrm{ICI}$

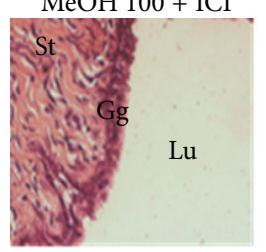

MeOH 300

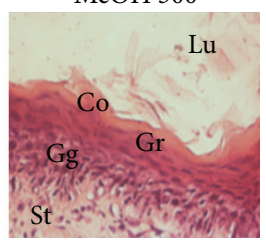

$\mathrm{MeOH} 300+\mathrm{ICI}$

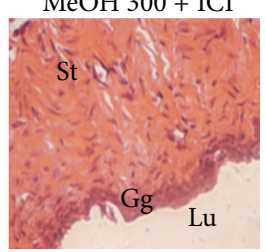

(b)

FIGURE 3: Effects of 3-day treatment with M. macrophylla extracts combined or not with ICI 182,780 on the vaginal epithelial height (a) and microphotographs (b). OVX = OVX animals treated with the vehicle (OVX); E2B = OVX animals treated with estradiol benzoate at $0.75 \mu \mathrm{g} / \mathrm{kg} \mathrm{BW}$; DCM $=$ OVX animals treated with the dichloromethane extract of $M$. macrophylla; $\mathrm{MeOH}=\mathrm{OVX}$ animals treated with the methanol extract of M. macrophylla. ${ }^{\#} P<0.05,{ }^{\# \#} P<0.01$, and ${ }^{\# \#} P<0.001$ compared with control; ${ }^{*} P<0.05$, ${ }^{* *} P<0.01$, and

${ }^{* * *} P<0.001$ compared with the same dose of each substance without ICI 182,780. Lu: lumen; Co: stratum corneum; Gr: stratum granulosum; Ge: stratum germinativum.

As shown in Figure 3(a), E2B treatment significantly $(P<0.001)$ increased the vaginal epithelial height by $266.71 \%$ as compared with control (OVX). Treatment with $M$. macrophylla extracts increased the vaginal epithelial height $(P<0.01)$ at all tested doses. Cotreatment of M. macrophylla extracts with ICI 182,780 (Faslodex: $300 \mu \mathrm{g} / \mathrm{kg}$ ) significantly $(P<0.01)$ abrogated the increase of vaginal epithelial height induced by E2B or M. macrophylla extracts treatment alone (Figure 3(a)). These effects were materialized in histological sections by the loss of the presence of stratification (stratum granulosum or stratum corneum) to a thin stratum germinativum consisting of few cell layers as observed in Control group (OVX) (Figure 3(b)).

As shown in Figure 4, treatment with E2B induced the increment of the diameter and the lumen of alveoli as well as an abundant eosinophil secretion in the lumen of alveoli. The $\mathrm{MeOH}$ extract increased the diameter of alveoli at all tested doses, however it induce eosinophil secretion only at the high dose. DCM extract failed to induce mammotrophic effect.
The results of the cotreatments with ICI 182,780 and DCM or $\mathrm{MeOH}$ M. macrophylla extracts showed that ICI 182,780 inhibits the mammotrophic effects induce by this substance alone; this was materialized by the loss of eosinophil secretion and the increment of acini height.

These results suggest that M. macrophylla induced its in vivo estrogenic effects through ERs.

\section{Discussion}

M. macrophylla has demonstrated pharmacological effects on estrogen target organs of female [18], osteoporosis [21], and male reproductive system of Wistar rats [22]. We hypothesize that $M$. macrophylla might mediate some of its actions by binding to the estrogen receptor, as it shares many estrogen-like actions in various physiological systems. To accomplish our goal, we used ICI 182,780 (Faslodex) which is the most potent estrogen receptor antagonist of the class of $7 \alpha$-alkylamide that has been approved for treatment of 


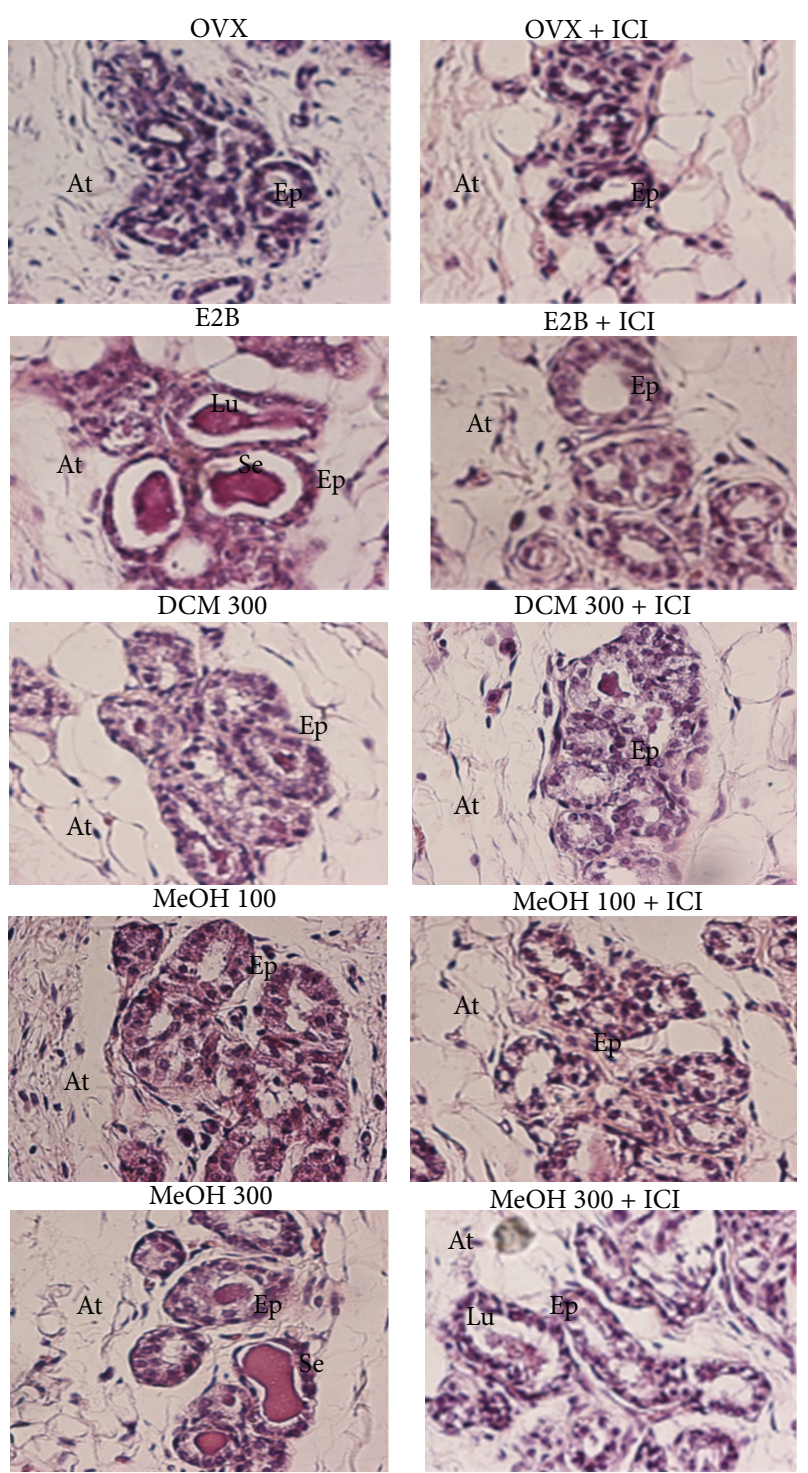

FIGURE 4: Effects of 3-day treatment with M. macrophylla extracts combined or not with ICI 182,780 on mammary gland. OVX = OVX animals treated with the vehicle (OVX); E2B = OVX animals treated with estradiol benzoate at $0.75 \mu \mathrm{g} / \mathrm{kgBW}$; DCM $=$ OVX animals treated with the dichloromethane extract of $M$. macrophylla; $\mathrm{MeOH}=$ OVX animals treated with the methanol extract of $M$. macrophylla. Lu: lumen of alveoli, Ep: alveoli epithelium, At: adipose tissue, Se: eosinophil secretion.

postmenopausal breast cancer patients who fail to respond to tamoxifen therapy [23]. It was reported that the ability of agonists of ERs to activate the transactivation liganddependent or ligand-independent is completely inhibited by ICI 182,780 [24]. In our study, ICI 182,780 significantly blocked M. macrophylla extracts-induced transactivation of both $\alpha$ and $\beta$ estrogen receptor subtypes in vitro. These results suggest that the induction of transactivation by $M$. macrophylla extracts is due to the binding of its secondary metabolites to ERs, thus corroborating the observation of many authors who also observed the inhibition of ERs ( $\alpha$ and $\beta$ ) transactivation in cellular systems [24-27].
Based on the fact that any beneficial effect obtained in vitro is not transferable in vivo because of the complexity of this later system, we also antagonized the plant extracts with ICI 182,780 in vivo in ovariectomized rats. The results showed that cotreatment of the extracts with ICI 182,780 significantly abrogated the increase of uterine wet weight, uterine, and vaginal epithelial height and uterine total protein levels after a 3-day treatment. Moreover, ICI 182,780 inhibits the effect of different treatments (E2B, DCM, and $\mathrm{MeOH}$ extracts) on mammary gland. These results corroborate with known ICI 182,780 effects. In fact, ICI 182,780 blocks endometrial proliferation and uterine growth in rats and inhibits growth of breast tumor cells both in cell culture and in vivo [25, 28]. ICI 182,780 is known not only for its inhibitory effects on the functional activity of estrogen receptors but also for its ability to reduce the cellular level of ERs [24]. Therefore, M. Macrophylla extracts while cotreated with ICI lose their effects probably due to a low level of ERs available to exhibit the estrogen-like effects obtained in the absence of ICI. This confirms that the active principles of M. macrophylla bind directly to ERs or at least are part of the regulatory complex at the promoter region of ERs target genes.

Phytoestrogens have been found to bind the estrogen receptor with an affinity 10 -fold to 1000 -fold lower than estrogen [29]. M. macrophylla has exhibited estrogen agonistic effects in the range of some well-characterized phytoestrogens; and these estrogenic effects were lost in the presence of ICI 182,780. Therefore, Millettia macrophylla should be classified as source of phytoestrogen like a number of plants consumed by humans such as soy, flax, red-clover, hops, citrus, grape, block cohosh, dong quai, ginseng, licorice, and wild Mexican yam [30]. Our results are interesting when considering the data from epidemiological surveys and nutritional intervention studies, indicating that some phytoestrogens ameliorate menopausal symptoms and are protective against a variety of disorders, including cardiovascular disease, cancer, hyperlipidemia, and osteoporosis [3134].

\section{Conclusion}

The estrogenic activities of $M$. macrophylla extracts may be due to one or more of its constituents that bind to ERs to induce their biological effects. More in vitro and in vivo studies will be needed to further characterise the molecular mechanism of action that underpins $M$. macrophylla extracts estrogenic activities. Nevertheless, M. macrophylla should be classified as a novel source of potent phytoestrogen.

\section{Conflict of Interests}

The authors declare that there is no conflict of interests regarding the publication of this paper.

\section{Acknowledgment}

Special thanks are due to the German Academic Exchange Service (DAAD) for material support. 


\section{References}

[1] J. T. Baker, R. P. Borris, B. Carté et al., "Natural product drug discovery and development: new perspectives on international collaboration," Journal of Natural Products, vol. 58, no. 9, pp. 1325-1357, 1995.

[2] A. Raja, P. Gajalakshmi, and M. Mohamed Mahroop Raja, "Drugs from the natural bio sources for human disease," International Journal of Pharmacology, vol. 6, no. 4, pp. 360363, 2010.

[3] World Health Organization, Traditional Medicine: Fact Sheet 134. 2003-05, World Health Organization, 2003.

[4] S. Hausmann-Muela, J. M. Ribera, and I. Nyamongo, "Healthseeking behaviour and the health system response," DCPP Working Paper 14, 2003.

[5] E. Kiawi, R. Edwards, J. Shu, N. Unwin, R. Kamadjeu, and J. C. Mbanya, "Knowledge, attitudes, and behavior relating to diabetes and its main risk factors among urban residents in Cameroon: a qualitative survey," Ethnicity and Disease, vol. 16, no. 2, pp. 503-509, 2006.

[6] D. A. Focho, W. T. Ndam, and B. A. Fonge, "Medicinal plants of Aguambu-Bamumbu in the Lebialem highlands, Southwest Province of Cameroon," African Journal of Pharmacy and Pharmacology, vol. 3, no. 1, pp. 1-13, 2009.

[7] L. K. Nzowa, L. Barboni, R. B. Teponno et al., "Rheediinosides A and $\mathrm{B}$, two antiproliferative and antioxidant triterpene saponins from Entada rheedii," Phytochemistry, vol. 71, no. 2-3, pp. 254261, 2010.

[8] V. Kuete and T. Efferth, "Cameroonian medicinal plants: Pharmacology and derived natural products," Frontiers in Pharmacology, 2010.

[9] V. Kuete and T. Efferth, "Pharmacogenomics of Cameroonian traditional herbal medicine for cancer therapy," Journal of Ethnopharmacology, vol. 137, no. 1, pp. 752-766, 2011.

[10] D. Njamen, M. A. Mvondo, S. Djiogue, G. J. M. K. Wanda, C. B. M. Nde, and G. Vollmer, "Phytotherapy and womens reproductive health: the cameroonian perspective," Planta Medica, vol. 79, no. 7, pp. 600-611, 2013.

[11] H. M. Burkill, The useful plants of west tropical Africa, vol. 3, Royal Botanic Gardens, Kew, UK, 1st edition, 1985.

[12] G. J. M. K. Wanda, D. Njamen, E. Yankep et al., "Estrogenic properties of isoflavones derived from Millettia griffoniana," Phytomedicine, vol. 13, no. 3, pp. 139-145, 2006.

[13] J. T. Banzouzi, A. Prost, M. Rajemiarimirabo, and P. Ongoka, "Traditional uses of African Millettia species (Fabaceae)," International Journal of Botany, vol. 4, no. 4, pp. 406-420, 2008.

[14] D. Njamen, C. B. Magne Ndé, Z. Tanee Fomum, and G. Vollmer, "Effects of the extracts of some tropical medicinal plants on estrogen inducible yeast and Ishikawa screens, and on ovariectomized Wistar rats," Pharmazie, vol. 63, no. 2, pp. 164$168,2008$.

[15] G. J. M. Ketcha Wanda, G. Kretzschmar, D. Njamen, M. Tagatsing Fotsing, E. Yankep, and G. Vollmer, "Modulation of some estrogen-responsive genes in the vena cava of ovariectomised Wistar rats by griffonianone $\mathrm{C}$, an isoflavone derived from Millettia griffoniana Baill. (Fabaceae)," Fitoterapia, vol. 81, no. 8, pp. 1232-1238, 2010.

[16] I. O. Lawal, N. E. Uzokwe, A. B. I. Igboanugo et al., "Ethno medicinal information on collation and identification of some medicinal plants in Research Institutes of South-west Nigeria," African Journal of Pharmacy and Pharmacology, vol. 4, no. 1, pp. 001-007, 2010.
[17] M. D. Wasserman, C. A. Chapman, K. Milton, J. F. Gogarten, D. J. Wittwer, and T. E. Ziegler, "Estrogenic plant consumption predicts red colobus monkey (Procolobus rufomitratus) hormonal state and behavior," Hormones and Behavior, vol. 62, no. 5, pp. 553-562, 2012.

[18] S. Zingue, D. Njamen, J. Tchoumtchoua et al., "Effects of Millettia macrophylla (Fabaceae) extracts on estrogen target organs of female wistar rat," Journal of Pharmacological Sciences, vol. 123, no. 2, pp. 123-120, 2013.

[19] M. F. W. Festing, "Suitability of the rat for different investigations in," in Inbred and Genetically Defined Strains of Laboratory Animals-part I, Mouse and Rat, P. L. Altman and D. D. Katz, Eds., pp. 237-238, Federation of American Societies for Experimental Biology, Bethesda, Md, USA, 1979.

[20] A. G. Gornall, C. J. Bardawill, and M. M. David, "Determination of serum proteins by means of the biuret reaction," The Journal of Biological Chemistry, vol. 177, no. 2, pp. 751-766, 1949.

[21] S. Zingue, D. Njamen, M. A. Mvondo, and C. B. Magne Nde, "Preventive effects of the methanol soluble fraction of Millettia macrophylla Benth (Fabaceae) on an osteoporosis-like model of ovariectomized Wistar rats," Journal of Complementary and Integrative Medicine, vol. 11, no. 2, pp. 83-92, 2014.

[22] S. Zingue, C. B. Magne Nde, and D. Njamen, "The methanolsoluble fraction of Millettia macrophylla (Fabaceae) stem bark endowed with estrogenic properties has adverse effects on the male reproductive system of Wistar rats," Journal of Basic and Clinical Physiology and Pharmacology, 2014.

[23] A. E. Wakeling and J. Bowler, "ICI 182,780, a new antioestrogen with clinical potential," Journal of Steroid Biochemistry and Molecular Biology, vol. 43, no. 1-3, pp. 173-177, 1992.

[24] A. Howell, CK. Osborne, C. Morris, and AE. Wakeling, "ICI 182,780 (Faslodex): development of a novel, "pure" antiestrogen," Cancer, vol. 89, no. 4, pp. 817-825, 2000.

[25] A. E. Wakeling, M. Dukes, and J. Bowler, "A potent specific pure antiestrogen with clinical potential," Cancer Research, vol. 51, no. 15, pp. 3867-3873, 1991.

[26] R. Y. K. Chan, W. F. Chen, A. Dong, D. Guo, and M. S. Wong, "Estrogen-like activity of ginsenoside Rg1 derived from Panax notoginseng," Journal of Clinical Endocrinology and Metabolism, vol. 87, no. 8, pp. 3691-3695, 2002.

[27] S. Djiogue, D. Njamen, M. Halabalaki et al., "Estrogenic properties of naturally occurring prenylated isoflavones in U2OS human osteosarcoma cells: structure-activity relationships," The Journal of Steroid Biochemistry and Molecular Biology, vol. 120, no. 4-5, pp. 184-191, 2010.

[28] A. E. Wakeling, "The future of new pure antiestrogens in clinical breast cancer," Breast Cancer Research and Treatment, vol. 25, no. 1, pp. 1-9, 1993.

[29] K. Morito, T. Hirose, J. Kinjo et al., "Interaction of phytoestrogens with estrogen receptors $\alpha$ and $\beta$," Biological and Pharmaceutical Bulletin, vol. 24, no. 4, pp. 351-356, 2001.

[30] E. M. Umland, J. S. Cauffield, J. K. Kirk, and T. E. Thomason, "Phytoestrogens as therapeutic alternatives to traditional hormone replacement in postmenopausal women," Pharmacotherapy, vol. 20, no. 8, pp. 981-990, 2000.

[31] H. Adlercreutz and W. Mazur, "Phyto-oestrogens and Western diseases," Annals of Medicine, vol. 29, no. 2, pp. 95-120, 1997.

[32] L. W. Lissin and J. P. Cooke, "Phytoestrogens and cardiovascular health," Journal of the American College of Cardiology, vol. 35, no. 6, pp. 1403-1410, 2000. 
[33] T. Ranich, S. J. Bhathena, and M. T. Velasquez, "Protective effects of dietary phytoestrogens in chronic renal disease," Journal of Renal Nutrition, vol. 11, no. 4, pp. 183-193, 2001.

[34] A. Chandrareddy, O. Muneyyirci-Delale, S. I. McFarlane, and O. M. Murad, "Adverse effects of phytoestrogens on reproductive health: A report of three cases," Complementary Therapies in Clinical Practice, vol. 14, no. 2, pp. 132-135, 2008. 

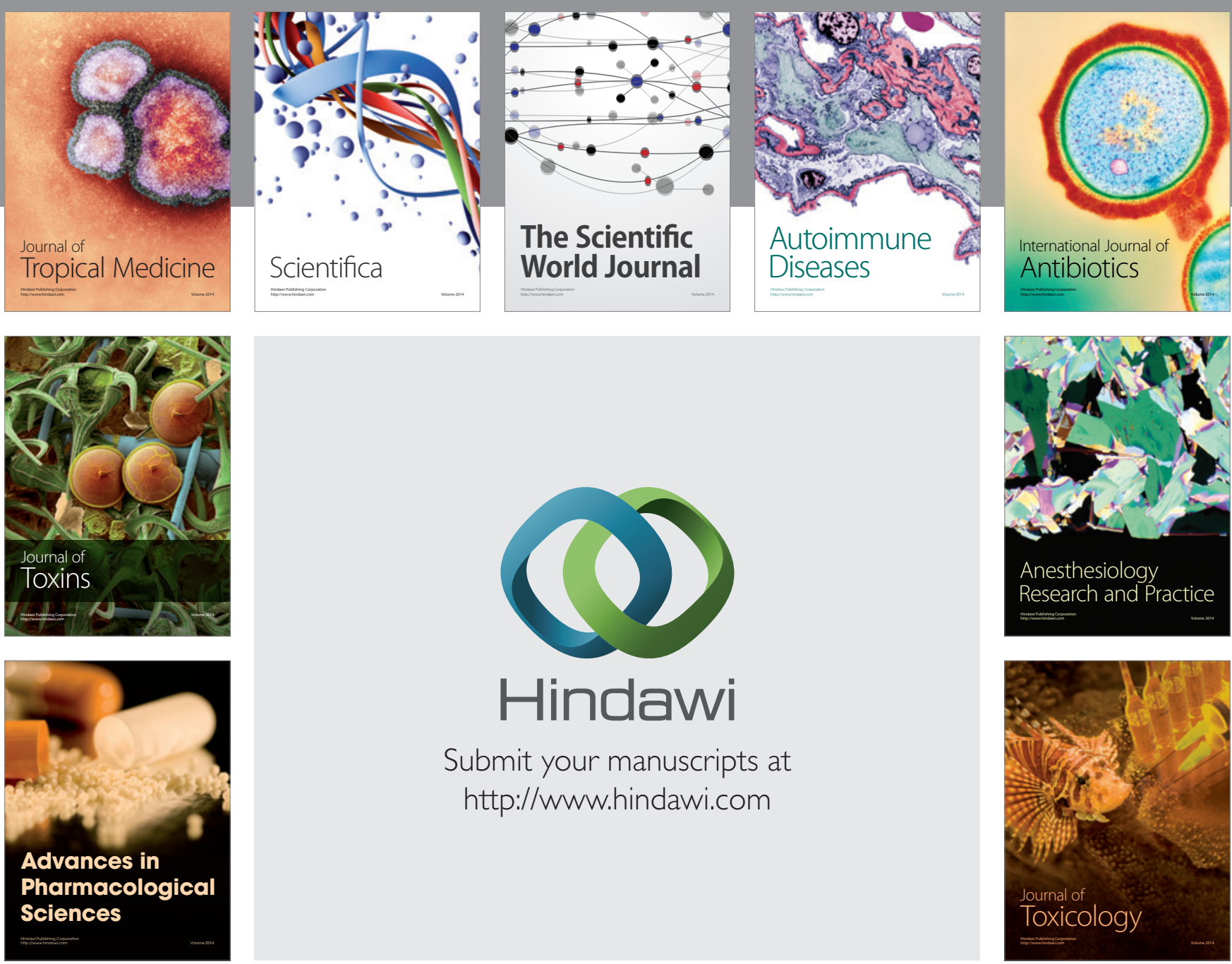

\section{Hindawi}

Submit your manuscripts at

http://www.hindawi.com
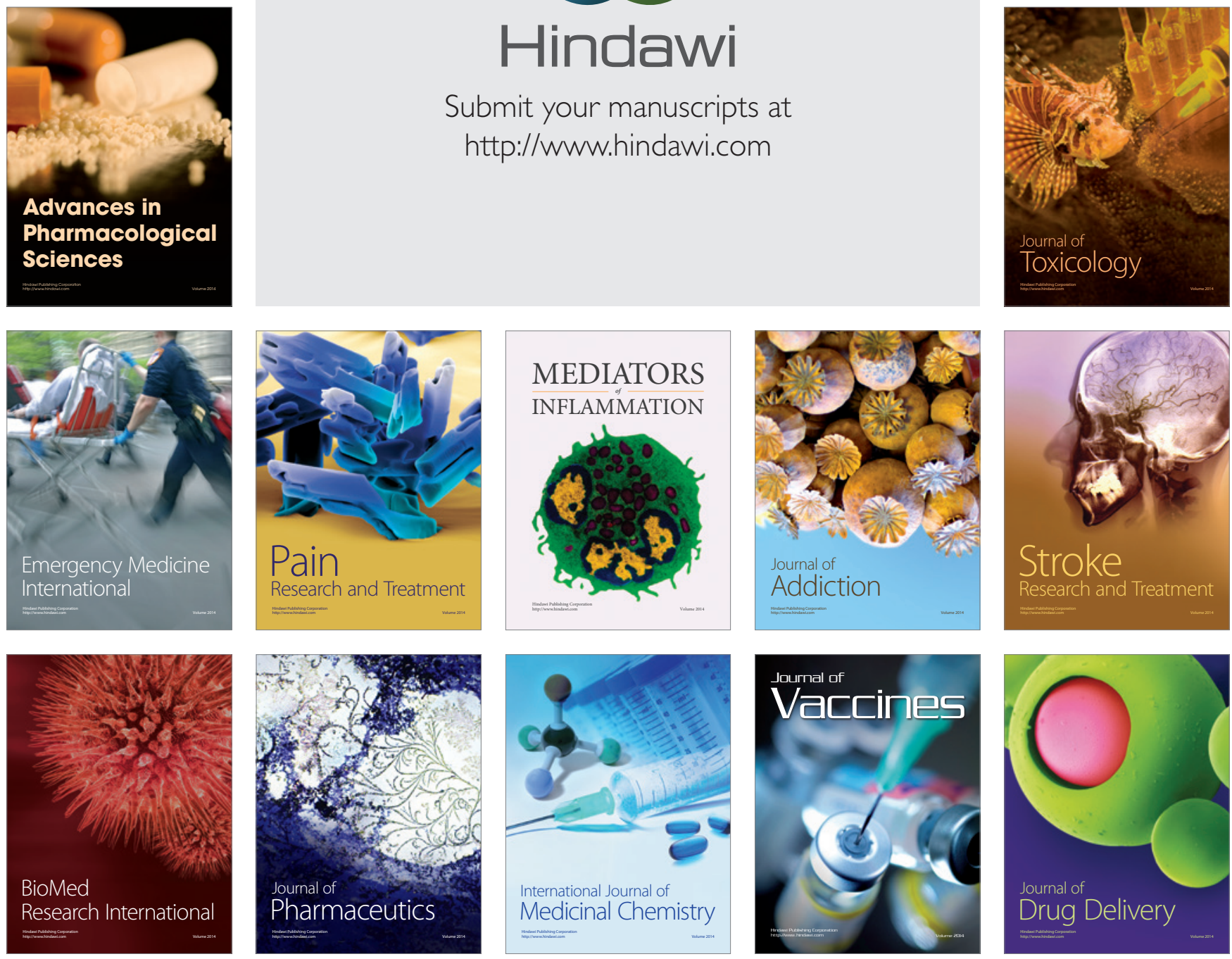